\title{
PEMISAHAN LOGAM BERAT MENGGUNAKAN MEMBRAN CAIR BERPENDUKUNG DENGAN VARIABEL KONSENTRASI ION LOGAM DAN PH FASA UMPAN
}

\author{
M. Cholid Djunaidi Abdul Haris,
}

Laboratorium Kimia Analitik Jurusan Kimia

Fakultas MIPA Universitas Diponegoro Semarang 50275

\begin{abstract}
ABSTRAK.
Telah dilakukan penelitian tentang pemisahan logam berat $\mathrm{Ag}, \mathrm{Cu}, \mathrm{Fe}, \mathrm{Ni}, \mathrm{Pb}$ dan $\mathrm{Zn}$ menggunakan teknik Membran Cair Berpendukung (SLM) dengan asam di2etilheksilfosfat (D2EHPA) sebagai pembawa. Pemisahan dilakukan dalam perangkat SLM selama $5 \mathrm{jam}$. Analisa dilakukan dengan mengukur konsentrasi logam di fasa umpan dengan AAS dan pengukuran konsetrasi ion hydrogen dengan $\mathrm{pH}$ meter. Hasil yang diperoleh memperlihatkan bahwa tranport dipengaruhi oleh konsentrasi logam, konsentrasi ion hidrogen dan selektifitas pembawa terhadap logam. Pembwa D2EHPA cukup selektifuntuk pemisahan logam berat dengan urutan: $\mathrm{Zn}>\mathrm{Ag}>\mathrm{Cu}>\mathrm{Pb}>\mathrm{Ni}$.
\end{abstract}

Kata kunci: SLM, logam berat, selektifitas, D2EHPA.

\section{SEPARATION HEAVY METALS USING SUPPORTED LIQUID MEMBRANE WITH METALS ION CONCENTRATION AND PH FEED PHASE VARIABLES.}

\begin{abstract}
Metals separation $\mathrm{Ag}, \mathrm{Cu}, \mathrm{Fe}, \mathrm{Ni}, \mathrm{Pb}$ and $\mathrm{Zn}$ has been conducted by Supported Liquid Membrane (SLM) technique with di2-ethylhexyl phosporic acid (D2EHPA) as carrier. The separation was carried out in SLM apparatus for 5 hours. Analysis was done by measuring the metal concentrations of feed phase by AAS and hydrogen concentration by pH meters. Results showed that the metals transport was influenced by metal concentration gradient, ion hydrogen concentration and carrier selectivity to metals. D2EHPA carrier was selective enough for heavy metal separations with sequence as the following: $\mathrm{Zn}>\mathrm{Ag}>\mathrm{Cu}>\mathrm{Pb}>\mathrm{Ni}$.
\end{abstract}

Keywords: SLM, heavy metal, selectivity, D2EHPA

\section{PENDAHULUAN}

Pemisahan selektif ion-ion logam berat dan toksik dari larutan limbah seringkali dibutuhkan dalam proses hidrometalurgi. Ekstraksi pelarut merupakan metode yang biasa digunakan untuk memisahkan beberapa ion logam dari larutan. Penggunaan ekstraksi pelarut sebagai unit operasi dalam hidrometalurgi sekarang digunakan secara luas untuk logam-logam dari berbagai macam bahan mentah termasuk bijih tingkat rendah, bahan sisa dan limbah ${ }^{[1]}$.

Dengan meningkatnya kebutuhan logam berat sebagai material utama dalam proses produksi, maka perlu dikembangkan metoda pemisahan dengan kinerja tinggi dan ekonomis untuk memperoleh kembali logam-logam dari bijih tingkat rendah dan sumber-sumber sekunder. Biasanya pemisahan dengan teknik ekstraksi pelarut biasa akan memerlukan jumlah ekstraktan yang banyak dan memerlukan waktu lama.

Berdasarkan kelemahan tersebut, maka teknik pemisahan yang sedang dikembangkan adalah pemisahan dengan teknik membran cair yang didasarkan pada trans- por ion logam melalui membran cair yang mengandung senyawa pembawa yang mobil. Pemisahan dengan teknik membran cair secara garis besar dapat dibagi dua yaitu membran cair emulsi (Emulsion Liquid Membrane, ELM) yang disebut juga membran cair bersurfaktan dan membran cair berpendukung (Supported Liquid Membrane, SLM).

Teknik pemisahan dengan membran cair berpendukung dilakukan pertama kali oleh Danesi dan Reicheley-Yinger ${ }^{[2]}$. Teknik SLM didasarkan pada distribusi cair-cair pada kondisi non-kesetimbangan. Zat pengekstrak dalam fasa organik yang ditempatkan dalam membran polimer berpendukung berpori, berfungsi sebagai senyawa pembawa. Transpor logam melalui SLM merupakan kombinasi antara proses ekstraksi dan pemisahan. Ekstraksi yang terjadi pada dasarnya sama seperti yang terjadi pada ekstraksi pelarut biasa, tetapi proses transpor lebih ditekankan pada masalah kinetika daripada parameter kesetimbangan.

Membran cair telah dikembangkan dan dipelajari untuk pemisahan logam toksik dan logam bernilai. Tek- 
nik didasarkan pada proses distribusi cair-cair, yang dilakukan dengan menggunakan agen pengekstrak seperti senyawa pembawa dalam transpor berfasilitas. Senyawa pembawa yang umum digunakan untuk memisahkan logam adalah ekstraktan pensolvasi seperti tri-n-butil fosfat yang digunakan untuk memperoleh logam dari media nitrat, ekstraktan penukar kation termasuk asam organofosfat, fosfonat, asam fosfonat dan asam karboksilat bisa digunakan untuk media asam hidroklorida, nitrat atau sulfat, dan ekstraktan penukar anion seperti garam ammonium kuartener. Dari sejumlah besar reagen pengekstrak ini, organofosfat adalah salah satu yang paling banyak dipelajari, khususnya D2EHPA ${ }^{[1,3]}$.

Membran cair berpendukung menggunakan membran berpori yang diimpregnasi dengan pembawa pengompleks untuk memisahkan fasa umpan dan penerima. Teknik SLM merupakan satu dari jenis membran cair yang mudah dibuat. Teknik tersebut telah digunakan tidak hanya untuk studi transpor, tapi juga pemisahan multi komponen. Teknik SLM telah memperlihatkan kemampuannya yang efektif dan luas untuk recovery berbagai larutan encer, seperti logam-logam, hidrokarbon, senyawa-senyawa yang penting secara biologi, campuran gas, asam dan basa lemah, fenol dari air limbah dan pemisahan amina ${ }^{[4]}$.

Pada penelitian ini dilakukan pemisahan selektif ion logam $\mathrm{Ag}, \mathrm{Pb}, \mathrm{Cu}, \mathrm{Zn}, \mathrm{Ni}, \mathrm{Fe}$ dengan teknik SLM menggunakan pembawa D2EHPA. Pembawa tersebut digunakan karena kestabilan yang tinggi dan selektivitasnya terhadap logam-logam serta kelarutan yang sangat rendah dalam fasa air ${ }^{[5]}$.

\section{METODA PENELITIAN}

Variabel yang diteliti dalam penelitian ini adalah pengaruh konsentrasi logam berat dan $\mathrm{pH}$ fasa umpan. Untuk mengetahui pengaruh konsentrasi logam dilakukan pengadukan dengan konsentrasi larutan umpan 5, 10 dan 15 ppm pada $\mathrm{pH} 3$, sedangkan untuk mengetahui pengaruh $\mathrm{pH}$ fasa umpan dilakukan pengadukan pada konsentrasi logam $10 \mathrm{ppm}$. Variasi $\mathrm{pH}$ yang dilakukan adalah pada $\mathrm{pH}$ fasa umpan 2,3 dan 4 .

Larutan umpan merupakan campuran logam-logam berat $\mathrm{AgNO}_{3}, \mathrm{~Pb}\left(\mathrm{NO}_{3}\right)_{2}, \mathrm{ZnSO}_{4}, \mathrm{NiSO}_{4}, \mathrm{CuSO}_{4}$ dan $\mathrm{FeSO}_{4}$ dalam media asam nitrat. Fasa umpan yang digunakan 5, 10 dan 15 ppm $100 \mathrm{~mL}$. Fasa penerima di- gunakan $\mathrm{HNO}_{3}$ 0,1 $\mathrm{M}$. Pengaturan $\mathrm{pH}$ dilakukan dengan menggunakan $\mathrm{pH}$ meter Metrohm. Fasa membran dibuat dengan merendam membran pori politetrafluoroetilen (PTFE) dari Whatman dengan ukuran pori 0,5 $\mu \mathrm{m}$ dan diameter $47 \mathrm{~mm}$ ke dalam pelarut kerosen. Kerosen sebelum digunakan didistilasi dulu dengan menggunakan $\mathrm{H}_{2} \mathrm{SO}_{4}$ dengan perbandingan volume 100:1 Sebagai senyawa pembawa digunakan D2EHPA. Larutan di kedua fasa diaduk dengan kecepatan 500 rpm selama 300 menit. Sampel diambil setelah 300 menit pengadukan dari fasa umpan dan fasa penerima sebanyak $20 \mathrm{~mL}$ dari larutan umpan. Deteksi konsentrasi ion logam dilakukan dengan AAS Perkin Elmer 5100 PC dan Hitachi, sedangkan deteksi konsentrasi ion hidrogen dilakukan dengan $\mathrm{pH}$ meter Metrohm.

\section{HASIL DAN PEMBAHASAN}

Pada transpor yang dibantu oleh pembawa penukar kation (D2EHPA) peranan $\mathrm{pH}$ sangat penting, karena dalam sistem ion tanding, ion hidrogen pada fasa penerima akan berperan sebagai pengganti ion logam, berikatan dengan senyawa pembawa kemudian dilepaskan ke fasa umpan sebagai pengganti ion logam berat. Dalam sistem SLM terjadi proses transpor tandingan ${ }^{[6]}$ yang termasuk transpor pasif dengan bantuan senyawa pembawa ${ }^{[7]}$. Gugus hidroksil D2EHPA melepas $\mathrm{H}^{+}$ dan mengikat kation logam pada fasa umpan kemudian membawanya melalui membran dan melepas ion logam tersebut ke dalam fasa penerima. Bersamaan dengan itu, gugus hidroksil D2EHPA kembali mengikat $\mathrm{H}^{+}$yang ada di fasa penerima dan melepasnya ke dalam fasa umpan. Proses tersebut terjadi secara bolakbalik dan kontinyu.

Persamaannya ditulis sebagai berikut:

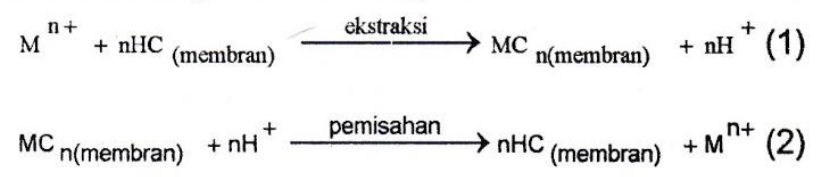

dengan $\mathrm{HC}$ adalah D2EHPA dan M adalah ion logam. spesi yang tertranspor. Untuk melihat hubungan konsentrasi logam berat dengan persen transpor dapat dilihat pada Gambar 1. 


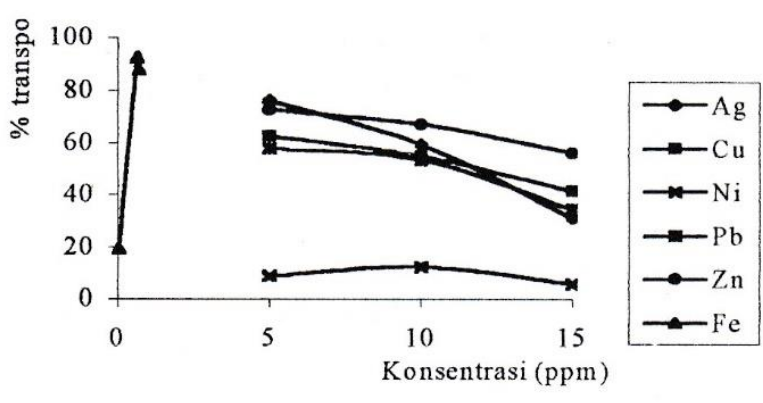

Gambar 1. Kurva hubungan konsentrasi (ppm) dengan \% transpor

Dari Gambar 1 di atas terlihat, semakin kecil konsentrasi logam berat di fasa umpan, transpor yang terjadi semakin besar. Hal ini berhubungan dengan kapasitas membran, bila konsentrasi bertambah, kapasitas membran menampung kompleks logam berat pembawa berkurang akibatnya persen transpor logam berat berkurang. Transpor logam berat ternyata tidak linier dengan kenaikan $\mathrm{pH}$ seperti yang tampak pada Gambar 2. Pada tanspor reaktif yang dibantu senyawa pembawa, peranan ion hidrogen sangat penting. Kompleks logam berat pembawa bisa mencapai fasa penerima dibantu oleh ion hidrogen tersebut. Sehingga bisa dikatakan bahwa selain gradien konsentrasi logam, gradien $\mathrm{pH}$ antara fasa umpan dan fasa penerima juga termasuk komponen gaya dorong transpor. Jika $\mathrm{pH}$ fasa penerima dibuat konstan, pada $\mathrm{pH}$ di bawah 3 , gradien konsentrasi ion hidrogen antara fasa umpan dan fasa penerima belum berarti. Sehingga transpor pada $\mathrm{pH}$ ini belum optimal. Pada pH 3 terjadi perbedaan koefisien distribusi $\left(\mathrm{K}_{\mathrm{d}}\right)$ larutan umpan dan $\mathrm{K}_{\mathrm{d}}$ fasa penerima yang optimal sehingga pada $\mathrm{pH}$ ini transpor paling efisien.

Tabel 1. Perubahan $\mathrm{pH}$ di fasa umpan dan penerima

\begin{tabular}{|c|c|c|}
\hline $\begin{array}{c}\text { Variabel } \\
\text { Konsentrasi } \\
\text { logam berat }\end{array}$ & $\begin{array}{c}\text { Penurunan } \mathrm{pH} \\
\text { fasa umpan } \\
\text { (satuan) }\end{array}$ & $\begin{array}{c}\text { Kenaikan } \mathrm{pH} \\
\text { fasa penerima } \\
\text { (satuan) }\end{array}$ \\
\hline 5 & 0.45 & 0.62 \\
\hline 10 & 0.63 & 0.58 \\
\hline 15 & 0.69 & 0.51 \\
\hline $\mathrm{pH}$ fasa umpan & & \\
\hline $\begin{array}{c}\text { Konsentrasi } \\
\text { logam 10 ppm }\end{array}$ & & \\
\hline 2 & 0.36 & 0.12 \\
\hline 3 & 0.63 & 0.58 \\
\hline 4 & 1.11 & 0.10 \\
\hline
\end{tabular}

Setelah lima jam, pengadukan dihentikan. Analisa hasil dengan $\mathrm{pH}$ meter menunjukkan adanya penurunan $\mathrm{pH}$ pada fasa umpan dan kenaikan $\mathrm{pH}$ pada fasa penerima akibat berpindahnya ion $\mathrm{H}^{+}$dari fasa umpan ke fasa penerima.

Kecepatan transpor logam berat sangat dipengaruhi oleh konsentrasi logam-logam berat di fasa umpan. Semakin besar konsentrasi logam berat di fasa umpan, maka antarmuka fasa umpan-membran akan jenuh oleh kompleks ini menjadi rendah karena besarnya ukuran Pada $\mathrm{pH} 4$, gradien $\mathrm{pH}$ umpan dan penerima memang lebih besar dari $\mathrm{pH}$ umpan 3. Tetapi hal tersebut menyebabkan juga transpor $\mathrm{HNO}_{3}$ sesuai persamaan 3 dari fasa penerima ke fasa umpan.

$\mathrm{H}^{+}(\mathrm{aq})+\mathrm{NO}_{3}^{-}+2 \mathrm{H}_{2} \mathrm{O}+(\mathrm{D} 2 \mathrm{EHPA})_{2}(\mathrm{o}) \Leftrightarrow$

(D2EHPA. $\left.\mathrm{H}_{2} \mathrm{O}\right)_{2} \cdot \mathrm{HNO}_{3}(\mathrm{o})$

Tabel2. Selektivitas Antara Logam dengan \% Transpor Tertinggi dengan Logam Lain pada Berbagai pH

\begin{tabular}{cccccc}
\hline \multirow{2}{*}{ pH } & $\mathbf{5 g}$ & $\mathrm{Cu}$ & $\mathrm{Ni}$ & $\mathrm{Pb}$ & $\mathrm{Zn}$ \\
\hline 2 & 0,283 & 0,194 & 0,003 & 0,750 & 1,000 \\
3 & 0,883 & 0,818 & 0,182 & 0,794 & 1,000 \\
4 & 1,000 & 0,663 & 0,405 & 0,427 & 0,920 \\
\hline
\end{tabular}

Akibat yang timbul adalah gradien konsentrasi asam dalam lapis difusi umpan bertambah dan menyebabkan pengurangan koefisien distribusi umpan $\left(\mathrm{K}_{\mathrm{df}}\right)$ logam berat, sedangkan koefisien distribusi pemisah $\left(\mathrm{K}_{\mathrm{ds}}\right)$ bertambah karena mekanisme solvasi. Selain itu, pada $\mathrm{pH} \cdot \mathrm{di}$ atas 3 kemungkinan terjadi endapan cukup besar mengingat $\mathrm{K}_{\mathrm{sp}}$ hidroksida logam berat sangat kecil.

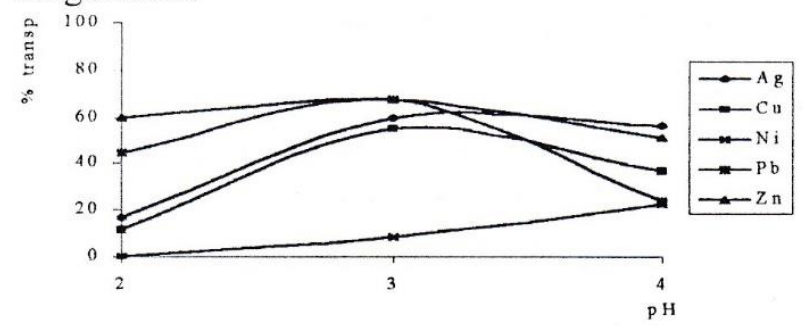

Gambar 2. Kurva hubungan $\mathrm{pH}$ dengan \% transpor

Dari Gambar 2 di atas dapat ditarik kesimpulan bahwa semua logam kecuali $\mathrm{Ni}$ dan $\mathrm{Fe}$, transpornya optimal pada $\mathrm{pH}$ 3. Transpor logam Ni mencapai optimal pada pH 4, sesuai dengan kondisi optimal ekstraksi pelarut $\mathrm{Ni}$ dengan D2EHPA ${ }^{[1]}$. Konsentrasi Fe dalam larutan sangat kecil sehingga tidak dimasukkan dalam Gambar 2.

Dari Gambar 2 diketahui, bahwa transpor optimal pada $\mathrm{pH} 3$ dimiliki oleh logam $\mathrm{Zn}$, oleh karena itu selektivitas dilakukan terhadap $\mathrm{Zn}$ yaitu dengan membagi persen transpor logam dengan persen transpor $\operatorname{logam} \mathrm{Zn}$. 
Selektivitas $\mathrm{Zn}$ terhadap logam berat $\mathrm{Ag}, \mathrm{Cu}, \mathrm{Ni}, \mathrm{Pb}$ berturut-turut adalah: 0,$883 ; 0,818 ; 0,182$ dan 0,794 . Terlihat bahwa logam Ni mempunyai selektivitas paling tinggi terhadap $\mathrm{Zn}$, diikuti selektivitas $\mathrm{Zn}$ terhadap logam-logam berat $\mathrm{Pb}, \mathrm{Cu}, \mathrm{Ag}$.

Jika dibandingkan dengan $\mathrm{pH} 3$, pada $\mathrm{pH} 2$ selektivitas $\mathrm{Zn}$ terhadap logam berat relatif lebih besar yaitu: 0,$283 ; 0,194 ; 0,003 ; 0,750$. Sehingga untuk tujuan pemisahan selektif lebih baik menggunakan pH umpan 2.

Pada $\mathrm{pH} 4$, transpor logam $\mathrm{Zn}$ dan Ag hampir sama dan Ni mendekati harga transpor $\mathrm{Pb}$, sehingga jika dibuat selektivitas $\mathrm{Zn}$ atau $\mathrm{Ag}$ terhadap logam lainnya, harganya tidak lebih dari pH 3. Sehingga dalam suatu penanganan limbah logam, lebih baik dilakukan bertahap. Tahap pertama adalah tahap ekstraksi logam pada $\mathrm{pH} 3$.

Setelah itu terhadap hasil dari tahap pertama dilakukan tahap berikutnya yaitu tahap eksplorasi menggunakan $\mathrm{pH} 2$.

Selektivitas pembawa D2EHPA terhadap logam-logam berat $\mathrm{Ag}, \mathrm{Cu}, \mathrm{Ni}, \mathrm{Pb}$ dan $\mathrm{Zn}$ adalah sebagai berikut: $\mathrm{Zn}>\mathrm{Ag}>\mathrm{Cu}>\mathrm{Pb}>\mathrm{Ni}$. Urutan selektivitas ini mirip dengan senyawa pembawa turunan fosfat yang lain yaitu asam di-2-etilheksilditiofosfat (DTPA) yaitu $\mathrm{Ag}>\mathrm{Cu}>\mathrm{Pb}>\mathrm{Ni}>\mathrm{Zn}^{[8]}$. Ag menempati urutan pertama karena selektivitas gugus tio terhadap logam Ag paling besar, sebaliknya terhadap logam $\mathrm{Zn}$.

\section{KESIMPULAN}

Besarnya transpor logam berat sangat dipengaruhi oleh konsentrasi ion logam fasa umpan, $\mathrm{pH}$ umpan dan adanya kompetisi antar ion atau selektivitas.
Selektivitas D2EHPA terhadap logam berat yang terdiri dari $\mathrm{Ag}, \mathrm{Cu}, \mathrm{Ni}, \mathrm{Pb}$ dan $\mathrm{Zn}$ adalah $\mathrm{Zn}>\mathrm{Ag}>\mathrm{Cu}>\mathrm{Pb}>\mathrm{Ni}$.

\section{UCAPAN TERIMA KASIH}

Penulis mengucapkan terima kasih kepada Bp. Kiswadi dan Bp. Sugeng Hartono atas bantuan moral dan material, Bp. Didik S Widodo dan Bp. W.H. Rahmanto atas saran dan koreksi yang telah diberikan, Saudari Noor Alia Widiastuti, Kusnaeni, Aciep Dwi Hadiyanto, Nurhadi, Wida Farida Kharismawaty, Enis Puspita Sari, dan Sutini serta mahasiswa Kimia angkatan 1998 atas bantuan yang telah diberikan.

\section{DAFTAR PUSTAKA}

1 Rydberg, J. Principles and Practices of Solvent Extraction; Marcel D: New York, 1992, pp 393-412.

2 Danesi, P.R., et.all., 1985, 3 (1\&2), 111-147.

3. Moreno, C., J. of. Membr. Sci. 1993, 121-126.

4. Walkowiak, W.; Gega, J. Transition Metal Cation Separation by Organophosporus Compound in Liquid Membrane Processes, C.S Symposium Series 642. Chemical Separation with Liquid Membrane; American Chemical Society: Washington, 1996, pp 181-193.

5. Spedding, F. H.; Daane, A. H. The Rare Earths; John Wiley and Sons Inc: New York, 1961, pp 571-605.

6. Misra, B. M., Symposium Series 642; Bartsch, R. A.; Way, J. D., Ed.; American Chemical Society: Washington, 1996, pp 37,361.

7. Mulder, M. Basic Principles of Membran Technology; Kluwer Academic Publisher: London, 1996, pp 340357.

8. Bomberg, L.; Lewin, Isaak.; Warshawsky, A. J. of Membr. Sci. 1992, 70, 31-39. 